Case study

\title{
Angka kebuntingan sapi perah dengan korpus luteum persisten setelah pemberian kombinasi prostaglandin $F_{2} \alpha$ dan gonadotropin
}

\section{The pregnancy rate of dairy cows with persistent corpus luteum after a combination treatment of prostaglandin $F_{2} \alpha$ and gonadotropin}

\author{
Nabila Azwani ${ }^{1}$, Endang Suprihati ${ }^{2}$, Sri Pantja Madyawati ${ }^{1}$, \\ Pudji Srianto ${ }^{1}$, Trilas Sardjito ${ }^{1}$ \\ ${ }^{1}$ Division of Veterinary Reproduction, ${ }^{2}$ Division of Animal Husbandry, \\ Faculty of Veterinary Medicine, Universitas Airlangga \\ *Corresponding author, e-mail: pudji-s@fkh.unair.ac.id \\ Open access under CC BY - SA license, DOI: 10.20473/ovz.v10i2.2021.59-64 \\ Received March 17 2021, Revised April 18 2021, Accepted July 282021 \\ Published online August 172021
}

\begin{abstract}
This case study aims to determine the effect of a combination of prostaglandin $\mathrm{F}_{2} \alpha\left(\mathrm{PGF}_{2} \alpha\right)$ with Gonadotropin (PG-600), and human chorionic gonadotropin (hCG) on the estrus and pregnancy rates in Holstein Friesian (HF) cows with persistent corpus luteum (PCL). A total of 15 Holstein Friesian (HF) dairy cows aged 3-5 years with body condition score (BCS) 5-7 (scale 1-9) diagnosed with PCL, were injected with $7.5 \mathrm{mg} \mathrm{PGF}_{2} \alpha$ intra-vulvar submucosa. Cows were then divided into three treatment groups. Group P0 was not given the combination treatment, while P1 group was injected with a combination of 300 IU PG-600 and 150 IU hCG, meanwhile P2 group was was injected with a combination of 300 IU PG-600 and 300 IU hCG intra-muscularly. The PGF $2 \alpha$ and PG-600 injections were carried out on the same day PCL was diagnosed. Meanwhile, the injection of hCG was carried out at the same time as the AI. The Pregnancy examination was performed 90 days after AI through rectal palpation. The results showed that all treated cows were estrus observed with the fastest onset of estrus was the P2 group, that was significantly different $(p<0.05)$ compared to the P0 and P1 groups. All treated cows were diagnosed as pregnant. It can be concluded that the administration of $\mathrm{PGF}_{2} \alpha$ or its combination with gonadotropins in HF cows with PCL could result in $100 \%$ estrus and pregnancy rates.
\end{abstract}

Keywords: Artificial insemination, corpus luteum persistent, dairy cows, estrus, pregnancy rate

\section{PENDAHULUAN}

Pada masa pandemi Covid-19 ini asupan makanan dan minuman yang bergizi tinggi sangat diperlukan untuk memperkuat daya tahan tubuh, salah satunya melalui konsumsi susu (Rizki et al., 2021). Kebutuhan susu di Indonesia setiap tahun semakin meningkat, karena semakin tinggi pertumbuhan penduduk dan semakin tinggi pula kesadaran terhadap pentingnya nilai gizi yang terkandung di dalamnya (Wulandari dan Bowo, 2019). Hal utama dalam suatu peternakan sapi perah adalah hasil susu yang diproduksi oleh ternak. Beberapa upaya untuk meningkatkan produksi susu dapat dicapai dengan meningkatkan produktivitas atau populasi sapi perah laktasi (Christi et al., 2020). Pemerintah membuat program Upaya Khusus Sapi Indukan Wajib Bunting (UPSUS SIWAB) dalam rangka mempercepat pencapaian peningkatan populasi di dalam negeri guna memenuhi permintaan konsumsi masyarakat 
Indonesia serta meningkatkan efisiensi dan efektivitas usaha budidaya ternak ruminansia (Saade et al., 2021). Target dari program Upsus Siwab adalah menanggulangi gangguan reproduksi agar sapi beranak setahun sekali. Salah satu gangguan reproduksi yang menjadi penyebab rendahnya efisiensi reproduksi adalah korpus luteum persisten (Tagesu, 2018)

Korpus luteum persisten (KLP) merupakan keadaan korpus luteum tidak mengalami regresi dan tetap tinggal pada ovarium dalam waktu yang lama (Strüve et al., 2013). Regresi korpus luteum dilakukan oleh hormon prostaglandin $\mathrm{F}_{2} \alpha\left(\mathrm{PGF}_{2} \alpha\right)$ yang dihasilkan oleh endometrium. Kegagalan regresi korpus luteum tersebut disebabkan oleh peradangan pada dinding endometrium yang mengakibatkan hormon $\mathrm{PGF}_{2} \alpha$ tidak mampu meregresi Korpus luteum. Gejala klinis yang sering terlihat adalah anestrus dalam waktu yang lama sehingga proses reproduksi menjadi terhenti (Magata et al., 2012). Terapi klinis terhadap KLP dapat dilakukan dengan pelepasan korpus luteum dengan cara pemijatan melalui palpasi per reaktal, pemberian yodin intra uterin, dan pemberian $\mathrm{PGF}_{2} \alpha$ (Pal dan Dar, 2020). Diantara beberapa macam terapi klinik tersebut pemberian $\mathrm{PGF}_{2} \alpha$ adalah yang umum dilakukan, baik secara subkutan, intra muskuler, intra uterin maupun submucosa vulva (Parmar et al., 2016). Pemberian $\mathrm{PGF}_{2} \alpha$ bertujuan untuk meregresikan korpus luteum, khususnya pada kasus anestrus yang disebabkan oleh korpus luteum persisten, sehingga dapat birahi kembali (Noguchi et al., 2017). Namun, persentase estrus dan kebuntingan yang terjadi kurang memuaskan.

Pada penggunaan $\mathrm{PGF}_{2} \alpha$ dapat terjadi kegagalan berovulasi pada sapi perah meskipun dilakukan dua kali penyuntikan (Berg et al., 2020). Kegagalan birahi dan ovulasi dapat terjadi karena kurangnya kematangan folikel atau kegagalan ovulasi. Stimulasi pertumbuhan dan pematangan folikel dapat dilakukan dengan penyuntikan PMSG dosis rendah (Putro et al., 2020). Sedangkan human Chorionic Gonadotropi (hCG) mempunyai efek menyerupai Luteinizing Hormon (LH), yang berfungsi untuk menginduksi ovulasi (Choi dan Smitz, 2014). Sejauh ini belum pernah dilakukan pengobatan KLP menggunakan kombinasi hormon $\mathrm{PGF}_{2} \alpha$. Sehubungan dengan hal itu maka studi kasus ini membahas pemberian kombinasi $\mathrm{PGF}_{2} \alpha$ dengan Gonadotropin (PG600 dan hCG) terhadap waktu timbul birahi dan angka kebuntingan ternak sapi perah yang mengalami KLP.

\section{MATERI DAN METODE}

\section{Lokasi kasus}

Penanganan kasus ini dilakukan di Koperasi Unit Desa (KUD) Tani Wilis, Kecamatan Sendang Kabupaten Tulungagung yang terletak pada $7^{\circ} 95^{\prime} 07^{\prime}$ ' lintang selatan dan $11^{\circ} 83^{\prime}$ ' 95" bujur timur, pada bulan Maret - Juni 2019. Secara topografi, wilayah kerja KUD Tani Wilis merupakan lereng bagian tenggara gunung Wilis yang relatif subur yang terletak pada ketinggian $785 \mathrm{~m}$ di atas permukaan laut. Iklim tropis basah dan kering dengan dua musim, yaitu musim penghujan dan musim kemarau. Suhu udara bervariasi antara $21^{\circ}-32^{\circ} \mathrm{C}$, dengan curah hujan tahunan 1.400-1.800 mm dan jumlah hari hujan berkisar antara 90-120 hari hujan per tahun (Bapeda Kabupaten Tulungagung, 2018).

\section{Diagnosis}

Sapi perah Friesian Holstein (FH) umur 3-5 tahun dengan skor kondisi tubuh (Body Condition Score, BCS 5-7, skala 1-9), yang mengalami korpus luteum persisten, dengan kriteria sudah pernah beranak, berdasarkan catatan medik tidak menunjukkan tanda-tanda birahi selama lebih dari satu siklus birahi, dan terdapat korpus luteum persisten pada pemeriksaan palpasi rektal oleh dokter hewan setempat.

\section{Terapi hormon}

Sebanyak 15 ekor sapi FH yang didiagnosis mengalami KLP disuntik dengan $\mathrm{PGF}_{2} \alpha$ (Dinoprost, Zoetis, Louvain-La-Neuve, Belgium) dengan dosis 7,5mg/ekor/ submukosa vulva, selanjutnya dibagi menjadi tiga kelompok perlakuan. Kelompok P0 tidak diberi perlakuan kombinasi, sedangkan kelompok P1 diberi terapi kombinasi PG-600 dengan dosis 300 IU/ekor/intra muskuler dan hCG 150 IU ekor/intra muskuler, dan kelompok P2 diberi terapi kombinasi 300 IU PG-600 dan 300 IU hCG. Penyuntikan $\mathrm{PGF}_{2} \alpha$ dan PG-600 dilakukan pada hari yang sama saat sapi terdiagnosis KLP. 
Pengamatan birahi dilakukan setiap pagi dan sore sejak penyuntikan $\mathrm{PGF}_{2} \alpha$ dan PG-600 sampai semua sapi terdata birahi. Penyuntikan hCG dilakukan bersamaan dengan waktu IB.

\section{Inseminasi Buatan}

Inseminasi buatan (IB) dilakukan 12-18 jam setelah munculnya tanda-tanda birahi, menggunakan semen beku sapi FH (Balai Besar Inseminasi Buatan, Singosari), dengan dosis 25 juta spermatozoa per midi straw $(0,5 \mathrm{~mL})$. Pelaksanaan IB oleh inseminator sesuai prosedur operasional standar. Semen beku dicairkan dalam air dengan suhu $37^{\circ} \mathrm{C}-38^{\circ} \mathrm{C}$ selama $15-$ 30 detik, lalu dibersihkan bagian luar straw dengan tisu steril, dimasukkan ke dalam laras inseminasi buatan, seal pada straw dipotong, ditutup plastic sheath, dikunci dan diinseminasikan pada posisi keempat. Pemeriksaan kebuntingan dilakukan 90 hari setelah IB dengan palpasi rektal.

\section{HASIL}

Hasil terapi hormon menunjukkan bahwa semua sapi FH tersebut mengalami birahi dengan waktu timbulnya birahi paling cepat pada kelompok P2 yang berbeda nyata $(\mathrm{p}<0,05)$ terhadap kelompok P0 maupun P1. Waktu timbulnya birahi antara kelompok P0 dengan $\mathrm{P} 1$, dan antara kelompok $\mathrm{P} 1$ dan $\mathrm{P} 2$ tidak berbeda nyata $(p>0,05)$. Semua sapi FH dengan KLP yang di terapi hormon terdiagnosis bunting.

Tabel 1 Persentase birahi, waktu timbul birahi dan persentase kebuntingan sapi FH dengan KLP yang diterapi dengan $\mathrm{PGF}_{2} \alpha$, PG-600 dan hCG.

\begin{tabular}{|c|c|c|c|c|c|c|}
\hline & \multicolumn{3}{|c|}{ perlakuan } & \multirow{2}{*}{ birahi } & \multirow{2}{*}{$\frac{\text { timbulnya birahi }}{\text { (jam, rata-rata } \pm S D)}$} & \multirow{2}{*}{ kebuntingan } \\
\hline & $\mathrm{PGF}_{2} \alpha$ & PG-600 & $\mathrm{hCG}$ & & & \\
\hline P0 & $7,5 \mathrm{mg}$ & - & - & $100 \%$ & $251,40 \pm 46,78^{\mathrm{a}}$ & $100 \%$ \\
\hline P1 & $7,5 \mathrm{mg}$ & $300 \mathrm{IU}$ & $150 \mathrm{IU}$ & $100 \%$ & $203,40 \pm 32,20^{a b}$ & $100 \%$ \\
\hline $\mathrm{P} 2$ & $7,5 \mathrm{mg}$ & $300 \mathrm{IU}$ & $300 \mathrm{IU}$ & $100 \%$ & $193,80 \pm 26,29^{b}$ & $100 \%$ \\
\hline
\end{tabular}

Ulangan $=5 ; \mathrm{PGF}_{2} \alpha$ dan PG-600 disuntikkan saat KLP terdiagnosa; hCG disuntikkan saat inseminasi buatan (IB), 12-18 jam setelah munculnya tanda-tanda birahi; waktu timbulnya birahi dihitung dari penyuntikan $\mathrm{PGF}_{2} \alpha$ dan PG-600; kebuntingan didiagnosa 90 hari setelah IB dengan palpasi rektal.

\section{DISKUSI}

Sapi FH yang mengalami KLP dalam studi ini berada dalam skor kondisi tubuh yang ideal, yaitu 3-5 (skala 1-9) sebagai sapi perah (Netika et al., 2019). Sapi yang mengalami KLP, kadar progesteron tetap tinggi yang menyebabkan sapi menjadi anestrus dalam jangka panjang (Magata et al., 2012). Induksi luteolysis dengan $\mathrm{PGF}_{2} \alpha$ hanya efektif antara hari 6 dan 16 siklus atau terdapat corpus luteum yang aktif. Pemberian 25 mg $\mathrm{PGF}_{2} \alpha$ alami atau 250-500 g $\mathrm{PGF}_{2} \alpha$ sintetik secara intra muskuler diperlukan untuk meregresi CL pada sapi dan kerbau (Pal dan Dar, 2020). Sapi FH kelompok P0 menunjukan respons birahi $100 \%$ dengan waktu timbulnya birahi 251,40 $\pm 46,78$ jam setelah penyuntikan $\mathrm{PGF}_{2} \alpha$. Pada sapi FH yang hanya diterapi dengan $\mathrm{PGF}_{2} \alpha$ akan terjadi regresi korpus luteum, diikuti berhentinya produksi hormon progesteron (Pal dan Dar, 2020) dan hilangnya umpan balik negatif kepada hipothalamus dan hipofisa anterior (Hafez dan Hafez, 2000). Selanjutnya hipothalamus akan mensekresikan GnRH yang memicu disekresikan follicle stimulating hormone (FSH) dan luteinizing hormone (LH) oleh hipofisa anterior, sehingga terjadi pertumbuhan dan pematangan folikel yang menghasilkan estrogen (Hafizuddin et al., 2012; Stevenson et al., 2012). Pada saat estrogen mencapai kadar yang tinggi menyebabkan munculnya tanda-tanda birahi (Bernardi et al., 2015).

Pada sapi fase luteal yang bukan KLP, induksi luteolysis dengan $\mathrm{PGF}_{2} \alpha$ subkutan menghasilkan estrus 30,3\% (Pfeifer et al., 2018), sedangkan penggunaan $\mathrm{PGF}_{2} \alpha$ secara intra muskuler menghasilkan respons birahi bervariasi antara 34,3\% (Pfeifer et al., 2018), 70\% (Balumbi et al., 2019), 100\% (Budiasa dan Pemayun, 2019), dan penggunaan $\mathrm{PGF}_{2} \alpha$ secara submucosa vulva dengan estrus 79,8\% (Rovani 
et al., 2012). Waktu munculnya birahi setelah penyuntikan $\mathrm{PGF}_{2} \alpha$ intra muskuler juga bervariasi, antara 27- 69 jam (Fauzi et al., 2017), 53,28 jam (Balumbi et al., 2019), 62-67 jam (Malik, 2019), 65,60 \pm 8,26 jam (Budiasa dan Pemayun, 2019), 69 jam (Berg et al., 2020). Penyuntikan $\mathrm{PGF}_{2} \alpha$ secara intra uterin menghasilkan respons birahi 40,80 $\pm 6,19$ jam setelah penyuntikan (Budiasa dan Pemayun, 2019).

Angka kebuntingan pada sapi $\mathrm{FH}$ dengan KLP yang disuntik $\mathrm{PGF}_{2} \alpha$ sub mukosa vulva mencapai 100\% (kelompok P0, Tabel 1). Angka kebuntingan tersebut sama dengan laporan penggunaan kombinasi 300 IU PG-600 dan 100 IU hCG pada sapi perah FH hipofungsi ovarium (Masruro et al.,2020). Persentase tersebut lebih tinggi dibandingkan penggunaan $\mathrm{PGF}_{2} \alpha$ secara subkutan yaitu sebesar $41,3 \%$ (Pfeifer et al., 2018), dan secara intra muskuler yaitu $70 \%$ (Budiasa dan Pemayun, 2019), dan 77\% (Mukkun et al., 2021).

Pada sapi $\mathrm{FH}$ yang disuntik $\mathrm{PGF}_{2} \alpha$ dikombinasi dengan PG-600 dan hCG (P1 dan $\mathrm{P} 2$, Tabel 1) juga menghasilkan respons birahi dan kebuntingan 100\%, namun kelompok P2 menghasilkan respons birahi lebih cepat daripada kelompok yang lain. PG-600 mengandung 400 IU PMSG dan 200 IU hCG (Innamma dan Roongsitthichai, 2015). PMSG mempunyai aktivitas seperti FSH, yang berfungsi untuk menstimulir pertumbuhan, pematangan folikel dan produksi hormon estrogen (Nergiz dan Saribay, 2018; Zolbin et al., 2018). Laporan sebelumnya menyebutkan bahwa penyuntikan 2-4 IU PMSG/kg berat badan diikuti dengan penyuntikan $\mathrm{PGF}_{2} \alpha$ intra muskuler menghasilkan respons birahi antara 70-90\% dengan waktu munculnya birahi 74-98 jam setelah penyuntikan $\mathrm{PGF}_{2} \alpha$, dengan angka kebuntingan $75-85 \%$ (Fu et al., 2013). Induksi ovulasi dengan hCG terbukti dapat meningkatkan kesuburan sapi perah (De Rensis et al., 2008). Aktivitas hCG sama seperti LH yaitu untuk menstimulasi produksi estrogen dan progesteron. Peranan hCG adalah untuk merangsang ovulasi serta pembentukan dan pemeliharaan korpus luteum untuk menghasilkan progesteron (Smitz dan Platteau, 2020). Luteinizing Hormone bertanggung jawab untuk menginduksi ovulasi. Lonjakan $\mathrm{LH}$ menciptakan lingkungan untuk erupsi folikel dengan meningkatkan aktivitas enzim proteolitik yang melemahkan dinding ovarium yang memungkinkan terjadinya ovulasi (Holesh et al., 2021). Luteinizing Hormone mempercepat pematangan folikel dan ovulasi (Dozortsev dan Diamond, 2020). Dengan demikian, PMSG dan dosis hCG lebih tinggi yang disuntikkan pada kelompok P2 menguatkan peranan FSH dan LH endogen, mempercepat pematangan folikel dan ovulasi.

Terdapat beberapa faktor yang mempengaruhi keberhasilan untuk menimbulkan kembali birahi dan kebuntingan pada sapi FH yang mengalami KLP pada studi kasus ini, diantaranya ketersediaan air minum ad libitum, hijauan yang terdiri atas campuran rumput gajah dengan rumput lapangan, dan campuran gliresidae dengan kaliandra, serta pemberian konsentrat dan mineral. Pakan hijauan yang berkualitas (Erickson dan Kalscheur, 2020), serta kandungan lemak, keseimbangan energi, protein dalam konsentrat dan suplementasi mineral berpengaruh terhadap fertilitas induk sapi FH (Rodney et al., 2018). Tingginya persentase kebuntingan juga dipengaruhi oleh keberhasilan IB, yaitu kualitas semen, penanganan semen, deteksi birahi, ketepatan waktu IB, dan keterampilan inseminator (Mohammed, 2018).

\section{KESIMPULAN}

Pemberian $\mathrm{PGF}_{2} \alpha$ atau kombinasinya dengan gonadotropin pada sapi FH yang mengalami KLP dapat menghasilkan angka birahi dan kebuntingan 100\%.

\section{DAFTAR PUSTAKA}

Balumbi M, Supriatna I, Setiadi MA. 2019. Respons dan Karakteristik Estrus setelah Sinkronisasi Estrus dengan Cloprostenol pada Sapi Friesian Holstein. Acta Vet Indones. 7: 29-36.

Bapeda (Badan Pembangunan Daerah) Kabupaten Tulungagung. 2018. Rencana Pembangunan Jangka Menengah Daerah Kabupaten Tulungagung Tahun 2018-2023. http://bappeda.tulungagung.go.id/pocontent/uploads/RPJMD_Kab._Tulungagun 
g_Tahun_2018-2023.pdf (diakses 22 Mei 2021).

Berg HF, Heringstad B, Alm-Kristiansen AH, Kvale VG, Dragset KI, Waldmann A, Ropstad E, Kommisrud E. 2020. Ovarian follicular response to oestrous synchronisation and induction of ovulation in Norwegian Red cattle. Acta Vet Scand. 62: 16.

Bernardi S, Rinaudo A, Marini P. 2015. Cervical Mucus Characteristics and Hormonal Status at Insemination of Holstein Cows. Iran J Vet Res. 17: 45-9.

Budiasa MK, Pemayun TGO. 2019. Induksi Berahi dengan PGF2 Alfa dan Penyuntikan Gn-RH Setelah di Inseminasi Buatan pada Sapi Bali. Indones Med Vet. 8: 565-71.

Choi J, Smitz J. 2014. Luteinizing hormone and human chorionic gonadotropin: distinguishing unique physiologic roles. Gynecol Endocrinol. 30: 174-81.

Christi RF, Hermawan H, Salman LB. 2020. Distribution of Holstein Friesian Dairy Cattle Populations in KUD Gemah Ripah Sukabumi, West Java for Milk Production of during Lactation, Daily Milk Production, and Fat Levels. Chalaza J Anim Husb. 5: 15.

De Rensis F, Valentini R, Gorrieri F, Bottarelli E, Lopez-Gatius F. 2008. Inducing ovulation with hCG improves the fertility of dairy cows during the warm season. Theriogenology 69: 1077-82.

Dozortsev DI, Diamond MP. 2020. Luteinizing hormone-independent rise of progesterone as the physiological trigger of the ovulatory gonadotropins surge in the human. Fertil Steril. 114: 191-9.

Erickson PS, Kalscheur KF. 2020. Nutrition and feeding of dairy cattle. Anim Agric. 2020: 157-80.

Fauzi MR, Suyadi S, Susilawati T. 2017. Pengaruh Pemberian Prostaglandin F2 Alpha Terhadap Waktu Kemunculan Birahi dan Keberhasilan Inseminasi Buatan Sapi Brahman Cross (Bx) Heifers. J. Ilmu-Ilmu Peternakan 27: 39-43.

Fu SB, Zhang HL, Riaz H, Ahmad S, Wang XM, Li X, Hua GH, Liu XR, Guo AZ, Yang LG. 2013. Effects of different doses of PMSG on reproductive performance in Chinese Holstein dairy cows. Pak Vet J. 33: 209-12.

Hafez ESE, Hafez B. 2000. Reproductive cycles. In: Hafez ESE, Hafez B (Eds). Reproduction in Farm Animals. 7th Ed. Wiley-Blackwell, USA. 55-67.

Hafizuddin, Siregar TN, Akmal M. 2012. Hormon dan Perannya Dalam Dinamika Folikuler Pada Hewan Domestik. J Edu Sains Biol. 1: 21-4.

Holesh JE, Bass AN, Lord M. 2021. Physiology, ovulation. In: StatPearls. StatPearls Publishing, Treasure Island, Florida. Accessed $12 \quad$ April 2020. https://www.ncbi.nlm.nih.gov/books/NBK5 41132/>.

Innamma N, Roongsitthichai A. 2015. Reproductive Effects of PG600 in Female Pigs. Thai J Vet Med. 45: 493-8.

Magata F, Shirasuna K, Strüve K, Herzog K, Shimizu T, Bollwein H, Miyamoto A. 2012. Gene expressions in the persistent corpus luteum of postpartum dairy cows: distinct profiles from the corpora lutea of the estrous cycle and pregnancy. J Reprod Dev. 58: 445-52.

Malik A. 2019. Efek penyuntikan prostaglandin F2 $\alpha$ (PGF2 $\alpha$ ) terhadap timbul dan lama birahi Sapi Bali pada paritas yang berbeda. Ziraa'ah 44: 141-5.

Masruro NA, Mulyati S, Harijani N, Madyawati SP, Samik A, Ratnani H. 2020. Penggunaan kombinasi Gonadotropin untuk pengobatan hipofungsi ovarium pada sapi perah. Ovozoa 9: 23-7.

Mohammed A. 2018. Artificial Insemination and its Economical Significancy in Dairy Cattle: Review. Int $J$ Res Stud Microbiol Biotechnol. 4: 30-43.

Mukkun RRL, Yusuf M, Toleng AL, Sonjaya H and Hasrin H. 2021. Effectiveness of estrous synchronization using prostaglandin (PGF2 $\alpha$ ) in Bali cows. The 3rd International Conference of Animal Science and Technology. IOP Conf. Series: Earth Environ Sci. 788: 1-8.

Nergiz KB, Saribay MK. 2018. The Effect of PMSG Treatment on Pregnancy Rates in Synchronized Heifers using Norgestomet Ear Implants. Isr J Vet Med. 73: 11-7. 
Netika M, Darsono R, Utomo B, Mustofa I, Ismudiono I, Suprayogi TW. 2019. Hubungan antara body condition score (BCS) dengan produksi susu sapi perah Friesian Holstein (FH). Ovozoa 8: 89-93.

Noguchi M, Hirata M, Kawaguchi H, Tanimoto A. 2017. Corpus luteum Regression Induced by Prostaglandin F2 $\alpha$ in Microminipigs During the Normal Estrous Cycle. In Vivo 31: 1097-101.

Pal P, Dar MR. 2020. Induction and Synchronization of Estrus. In: Aral F, Payan-Carreira R, Quaresma M (Eds). Animal Reproduction in Veterinary Medicine. InTech, Rijeka, Croatia. 133-45.

Parmar SC, Parmar C, Patel JA. 2016. Use of PGF2 $\alpha$ in ovarian and uterine pathological conditions of bovine : a therapeutic approach. Explor Anim Med Res 6: 132-41.

Pfeifer LFM, Rodrigues WB, Casanova da Silva $\mathrm{K}$, Anache NA, Castro NÁ, Castilho EM, Nogueira E. 2018. Different protocols using PGF $2 \alpha$ as ovulation inducer in Nelore cows subjected to estradiol-progesterone timed AI based protocols. Theriogenology 120: 5660.

Putro KB, Amrozi A, Winarto A, Boediono A, Manalu W. 2020. Folikel Pre-Ovulatori Sapi PO Dara yang Distimulasi Menggunakan PMSG Dosis Rendah. Acta Vet Ina 8: 1-7.

Rizki A, Ariska RN, Asra S. 2021. Pelatihan pengolahan susu kambing menjadi kefir sebagai Probiotik peningkat sistem imun pada masa Covid-19. Glob Sci Soc. 3: 31-6.

Rodney RM, Celi P, Scott W, Breinhild K, Santos JEP, Lean IJ. 2018. Effects of nutrition on the fertility of lactating dairy cattle. J Dairy Sci. 101: 5115-33.

Rovani MT, Barreta MH, Ferreira R, Gasperin BG, Antoniazzi AQ, Festugatto R, Oliveira
JFC, Goncalves PBD. 2012. Luteolysis after the intravulvosubmucosal injection of prostaglandin F2 $\alpha$ in cattle: Systemic or local mechanism? Livest Sci. 148: 60-6.

Saade A, Ekasari K, Marhamasari I, Salman D. 2021. Breeders response to UPSUS Siwab's efforts to increase cattle population. The 1st International Conference on Environmental Ecology of Food Security. IOP Conf. Series: Earth Environ Sci. 681: 1-8.

Smitz J, Platteau P. 2020. Influence of human chorionic gonadotrophin during ovarian stimulation: an overview. Reprod Biol Endocrinol 18: 80.

Stevenson JS, Pulley SL, Mellieon Jr HI. 2012. Prostaglandin F2 $\alpha$ and gonadotropinreleasing hormone administration improve progesterone status, luteal number, and proportion of ovular and anovular dairy cows with corpora lutea before a timed artificial insemination program. J Dairy Sci. 95: 1831-44.

Strüve, K., Herzog, K., Magata, F, Piechotta M, Shirasuna K, Miyamoto A, Bollwein $\mathrm{H}$. 2013. The effect of metritis on luteal function in dairy cows. BMC Vet Res. 9: 244.

Tagesu A. 2018. Review on the Reproductive Health Problem of Dairy Cattle. J Dairy Vet Sci. 5: 1-12.

Wulandari S, Bowo P. 2019. Pengaruh Produksi, Konsumsi dan Harga Susu Sapi Nasional Terhadap Impor Susu Sapi. Econ Educ Anal J. 8: 1130-46.

Zolbin MM, Nematian S, Daghigh F, Namdar F, Zaree ST, Madadian M, Abbasi M, Mogahi SMHN, Takzaree N. 2018. PMSG and HCG hormones effect on the development and growth of ovarian follicles. J Contemp Med Sci. 4: 51-4. 